Www.jmscr.igmpublication.org

Impact Factor (SJIF): 6.379

Index Copernicus Value: 71.58

ISSN (e)-2347-176x ISSN (p) 2455-0450

crossref DOI: https://dx.doi.org/10.18535/jmscr/v6i3.65

Journal Of Medical Science And Clinical Research

IGM Publication

An Official Publication of IGM Publication

\title{
Comparative Study of Onlay and Pre-Peritoneal Mesh Repair in the Management of Ventral Hernias
}

\author{
Authors \\ Ritesh Dhanbhar ${ }^{1}$, Niranjan Dash ${ }^{2}$ \\ Department of General Surgery, DVVPFS Medical College, Ahmednagar \\ Corresponding Author \\ Ritesh Dhanbhar \\ Phone No : 9730772807, Email: riteshgjmptw@gmail.com
}

\begin{abstract}
Introduction: Ventral hernias is major problem in surgical practice and occurs in up to $11 \%$ of patients undergoing laparotomy. Argument for the ideal surgical procedure for placing mesh continues to be unsolved. Hence there is need of study to evaluate better technique between two most commonly used methods to repair ventral hernia by two methods onlay and sublay.

Aims and Objective: To compare complications of onlay and pre-peritoneal Mesh Repair in ventral hernias.

Materials and Methods: In this study 80 patients presenting with ventral hernia between July 2015 and July 2017 in our institute are included. Randomization done as even registration no will undergo onley mesh repair and odd registration no will undergo pre-peritoneal mesh repair.

Results: Mean duration of surgery in onlay Mesh repair was 50 min and that in pre-peritoneal mesh repair was 70 min. Seroma formation was seen $4(13.33 \%)$ patients of pre-peritoneal mesh repair and $7(23.33 \%)$ patient of onlay Mesh repair. Wound infection was seen 1(3.33\%) patients of pre-peritoneal mesh repair and 5(16.67\%) patient of onlay Mesh repair. Chronnic pain was seen 2(6.66\%) patients of pre-peritoneal mesh repair and 6(26.87\%) patient of onlay Mesh repair. Recurrence was observed only in patients with onlay mesh repair in 3 patients (10.0\%).

Conclusion: Onlay mesh repair is more associated with complication and recurrance than pre-peritoneal mesh repair. According to this study pre-peritoneal mesh repair is superior to onlay mesh repair.
\end{abstract}

\section{Introduction}

Ventral hernia is a protruberance of an abdominal viscus or part of a viscus through anterior abdominal wall occurring at any site other than inguinal region. Ventral hernia includes incisional hernias, paraumbilical hernias, umbilical hernia, epigastric hernias, and spigelian hernias, respectively. ${ }^{(1)}$

Patient takes medical advice for swelling, discomfort, acute pain, associated gastrointestinal symptoms or cosmetic symptoms.

Etiology for formation of ventral hernia is variable. Types of ventral hernias are spontaneous, congenital, and incisional hernias. In $90 \%$ of patients acquired defect is seen. Acquired defect is due to increased abdominal pressure. ${ }^{(2)}$ Abdominal pressure increase due to multiparous status, obesity, and cirrhosis with ascites. ${ }^{(3)}$ Various factors leading to formation of ventral hernias are obesity, ${ }^{(4)}$ older age, male gender, ${ }^{(5)}$ sleep apnea, ${ }^{(4)}$ emphysema and other chronic lung conditions, abdominal distention, steroids ${ }^{(6)}$, jaundice $^{(7,8)}$, Collagen defects ${ }^{(9)}$.

Incisional hernia is common complication of abdominal surgical procedures. Studies have shown that transverse incisions are associated 
with a reduced incidence of incisional hernia compared to midline vertical laparotomies, although data are far from conclusive. ${ }^{(10,11)}$

Debate for the ideal surgical approach for placing mesh has remain unanswered. Although each approach for placing mesh has its supporters. Our study comparis between two most commnly used onlay mesh repair and pre-peritoneal mesh repair for ventral hernia.

\section{Materials and Methods}

Patients presenting with ventral hernia admitted to our institute from July 2015 to July 2017 were preoperatively assessed clinically and by ultrasonography to confirm the diagnosis.

In this study 80 patient are included.

This was prospective obsrvational study.

Randomization done as even registration no will undergo onley mesh repair and odd registration no will undergo pre-peritoneal mesh repair.

Informed consent was given by patients.

\section{Inclusion Criteria}

All patients presenting with anterior abdominal wall hernias:
a. Umbilical hernias.
b. Epigastric hernias.
c. Paraumbilical hernias.
d. Incisional hernias.
e. Spigelian hernias.
Exclusion Criteria:
a. Groin hernia.
b. Divarication of recti.

\section{Types of Mesh Repair}

Onlay mesh repair

In this technique, hernial sac and its contents are reduced, aponeurosis is approximated using polypropylene suture and the prosthetic mesh is placed over the aponeurosis and fixed with proline suture material.

\section{Pre-peritoneal mesh repair}

In this technique, after reducing hernial sac and its contents, separation of peritoneum from abdominal wall is done. Mesh is placed between peritoneum and rectus sheath. Mesh is fixed to rectus sheath with polypropylene suture material.

\section{Results}

\section{1) Percentage Distribution of Ventral Hernias}

Most common type of ventral hernia was incisional hernia (40\%). Epigastric hernia was the least common type (10\%) (Table 1).

\section{Table No 1:}

\begin{tabular}{|l|c|c|}
\hline Type of hernia & Number & Percentage \\
\hline Incisional & 32 & $40 \%$ \\
\hline Paraumbilical & 27 & $33.75 \%$ \\
\hline Umbilical & 13 & $16.25 \%$ \\
\hline Epigastric & 8 & $10 \%$ \\
\hline
\end{tabular}

\section{2) Age Distribution}

Study showed that the maximum number of patients were in the 4th decade of life $(66.25 \%)$. There were no patients in the ageless than 20 years (Table 2)

\section{Table No 2:}

\begin{tabular}{|l|c|c|}
\hline Age in years & Patients & Percentage \\
\hline$<20$ & 0 & 0 \\
\hline $21-30$ & 13 & 16.25 \\
\hline $31-40$ & 53 & 66.25 \\
\hline$>40$ & 14 & 17.5 \\
\hline
\end{tabular}

\section{3) Sex Distribution}

Out of 80 cases, 53 patients $(66.25 \%)$ were females, and 27 patients $(33.75 \%)$ were males (Table 3).

\section{Table 3}

\begin{tabular}{|l|c|c|}
\hline Sex & Patients & Percentage \\
\hline Male & 27 & 33.75 \\
\hline Female & 53 & 66.25 \\
\hline
\end{tabular}

\section{4) Type of Previous Operation in Incisional Hernia}

In our study in cases with incisional hernia (32), 19 patient $(59.37 \%)$ had underwent tubectomy, 11 patient $(34.37 \%)$ had undergone lower segment caesarian section (LSCS), and 2 patient $(9.37 \%)$ had underwent hysterectomy (8.33\%) (Table 4).

\section{Table 4}

\begin{tabular}{|l|c|c|}
\hline Previous operation & Patients & Percentage \\
\hline Tubectomy & 19 & 59.37 \\
\hline LSCS & 11 & 34.37 \\
\hline Hysterectomy & 3 & 9.37 \\
\hline
\end{tabular}




\section{5) Mode of Presentation}

Most of the patients i.e. 67 patients $(83.75 \%)$ presented with swelling, 10 patients $(16.66 \%)$ with pain and swelling (Table 5).

Table 5

\begin{tabular}{|l|c|c|}
\hline Symptoms & Patients & Percentage \\
\hline Swelling & 67 & 83.75 \\
\hline Swelling and pain & 13 & 16.25 \\
\hline
\end{tabular}

\section{6) Associated Risk Factors or Illness}

In this study 33 patient (41.25) were multipara, 23 patients $(28.75 \%)$ were obese, 7 patients $(8.75 \%)$ were diabetic, 1 patient $(1.25 \%)$ was anemic, and one patient $(1.25 \%)$ was hypothyroid. Hence, obesity was the most common associated risk factor (Table 6).

\section{Table 6}

\begin{tabular}{|l|c|c|}
\hline Condition & Patients & Percentage \\
\hline Multipara & 33 & 41.25 \\
\hline Obesity & 23 & 28.75 \\
\hline Diabetes & 7 & 8.75 \\
\hline Anemia & 1 & 1.25 \\
\hline Hypothyroidism & 1 & 1.25 \\
\hline
\end{tabular}

\section{7) Content of the sac}

Out of 80 patients, 60 patients $(75.0 \%)$ had omentum, 19patients (23.75\%) had Small intestineand $(1.67 \%)$ had transverse colonas content of the sac. Hence, omentum was the most common content of the hernial sac (Table 7).

\section{Table 7}

\begin{tabular}{|l|c|c|}
\hline Content of the sac & Patients & Percentage \\
\hline Omentum & 60 & 75.0 \\
\hline Small intestine & 19 & 23.75 \\
\hline Transverse colon & 1 & 1.25 \\
\hline
\end{tabular}

\section{8) Type of Mesh Repair}

$40(50 \%)$ patients underwent pre-peritoneal mesh repair, and $40(50 \%)$ patients underwent onlay mesh repair (Table 8 ).

\section{Table 8}

\begin{tabular}{|l|c|c|}
\hline Type of mesh repair & Patients & Percentage \\
\hline Pre-peritoneal & 40 & 50 \\
\hline Onlay & 40 & 50 \\
\hline
\end{tabular}

\section{9) Duration of surgery}

Mean duration of surgery in Onlay Mesh repair was $50 \mathrm{~min}$ and that in pre-peritoneal Mesh repair was $70 \mathrm{~min}$. (Table9).

\section{Table 9}

\begin{tabular}{|l|c|}
\hline Type of mesh repair & Mean duration of surgery \\
\hline Onlay & $50 \mathrm{~min}$ \\
\hline Pre-peritoneal & $70 \mathrm{~min}$ \\
\hline
\end{tabular}

\section{0) Post-operative Complications}

Seroma was the most common complication followed by chronic pain and wound infection. Seroma was drained. Chronic pain was managed with analgesics and reassurance. Seroma was seen in 5 patients $(12.5 \%)$ and 9 patients $(22.5 \%)$ in preperitonial and onlay respectively. Wound infection was seen in 1 patient $(2.5 \%)$ and 7 patients $(17.5 \%)$ in preperitonial and onlay respectively. Chronic pain was seen in 3 patients $(7.5 \%)$ and 11 patients $(27.5 \%)$ in preperitonial and onlay respectively. Over all in preperitonial mesh repair had conplications in 9 patients $(22.5 \%)$ and onley mesh repair had complications in 27 patient $(67.5 \%)$ (Table 10).

\section{Table 10}

\begin{tabular}{|l|c|c|c|c|}
\hline Complication & Preperitoneal & Onlay & $\begin{array}{c}\text { Pre-peritoneal } \\
(\%)\end{array}$ & $\begin{array}{c}\text { Onlay } \\
(\%)\end{array}$ \\
\hline Seroma & 5 & 9 & 12.5 & 22.5 \\
\hline Wound infection & 1 & 7 & 2.5 & 17.5 \\
\hline Mesh infection & 0 & 0 & 0 & 0 \\
\hline Chronic pain & 3 & 11 & 7.5 & 27.5 \\
\hline Intestinal fistula & 0 & 0 & 0 & 0 \\
\hline Total & 9 & 27 & 22.5 & 67.5 \\
\hline
\end{tabular}

\section{1) Follow-up and Recurrence}

Patients were regularly followed up to 1 year. Recurrence was observed only in patients with onlay mesh repair. 4 patients (10\%) patients out of 40 patients who underwent onlay mesh repair had a recurrence (Table 11). 
Table 11

\begin{tabular}{|l|c|c|}
\hline Type of operation & Recurrence & Percentage \\
\hline Pre-peritoneal & 0 & 0 \\
\hline Onlay & 4 & 10 \\
\hline
\end{tabular}

\section{Discussion}

In this study 40 patients(50\%) underwent pre-peritoneal mesh repair, and 40 patients (50\%)underwent onlay mesh repair

Incidence of Incisional hernia was $40 \%$, paraumbilical hernia was $33.75 \%$, umbilical hernia was $16.25 \%$, epigastric hernia was $10 \%$. Similar incidence rate was seen in Bantu Rajsiddharth et al \%)Ventral hernias are common in patients age between 30 and 40 years $(66.25 \%)$ in our study. Youngest patient in our study was 22-year-old. Similar age distribution was seen in Bantu Rajsiddharth et al study. ${ }^{(12)}$

In our study found that ventral hernias are common among females (66.25\%). Ellis et al. study shows similar distribution of sex I. e. $64.6 \%$ of female population. ${ }^{(13)}$ Godara et al. series had a female population of $42.5 \%$. $^{(14)}$

Incisional hernias common after gynecological surgeries. Tubectomy was the most common predisposing surgery seen in 19 patients $(59.37 \%)$ followed by LSCS seen in 11 patients (34.37\%). Godara et al series also mentions gynecological surgeries as most common associated surgery. ${ }^{(14)}$

Most of the patients i.e. 67 patients $(83.75 \%)$ presented with swelling, 10 patients $(16.66 \%)$ with pain and swelling. Similar incience of swelling was seen in Bantu Rajsiddharth et al study. ${ }^{(12)}$

In females most precipitating factor was multiparity seen in 33 patient $(41.25 \%)$. Next precipitating factor was obesity see 23 patients $(28.75 \%)$. Other precipitating factor were, diabetis seen in 7 patients $(8.75 \%)$, anemia seen in 1 patient $(1.25 \%)$, and 1 patient $(1.25 \%)$ was hypothyroid. Similar result seen in Bantu Rajsiddharth et al study. ${ }^{(12)}$

Out of 80 patients, 60 patients(75.0\%) had omentum, 19 patients $(23.75 \%)$ had Small intestineand 1 patient (1.67\%) had transverse colonas content of the sac. Hence, omentum was the most common content of the hernial sac. In Bantu Rajsiddharth et al study also, omentum was most common content of hernial sac . ${ }^{(12)}$

Mean duration of surgery in Onlay Mesh repair was $50 \mathrm{~min}$ and that in pre-peritoneal Mesh repair was $70 \mathrm{~min}$. Godara et al., study reported a mean duration of $49.35 \mathrm{~min}$ for onlay and a mean duration of $63.15 \mathrm{~min}$ for pre-peritoneal mesh repair. ${ }^{(14)}$ In Gleysteen series mean duration for onlay and pre-peritoneal mesh repair were 42 and $70.5 \mathrm{~min}$ respectively. ${ }^{(15)}$

Seroma was seen in 5 patients $(12.5 \%)$ and 9 patients $(22.5 \%)$ in preperitonial and onlay mesh repair respectively. Wound infection was seen in 1 patient $(2.5 \%)$ and 7 patients $(17.5 \%)$ in preperitonial and onlay mesh repair respectively. Chronic pain was seen in 3 patients $(7.5 \%)$ and 11 patients $(27.5 \%)$ in preperitonial and onlay mesh repair respectively. Over all in preperitonial mesh repair had conplications in 9 patients $(22.5 \%)$ and onley mesh repair had complications in 27 patient $(67.5 \%)$. Godara et al study shows similar complication rate $(22.5 \%)$ in preperitonial mesh repair. ${ }^{(14)}$ But Godara et al study shows less complication rate $(15 \%)$ in onlay mesh repair. ${ }^{(14)}$ Onlay technique had more of seroma formation, due to the fact that onlay techniques require significant subcutaneous dissection to place mesh, which can lead to devitalized tissue with seroma formation or infection. The superficial location of the mesh also puts it in danger of becoming infected if there is a superficial wound infection. chronic pain in Onlay Mesh repair may be because mesh is placed below subcutaneous plane over the muscle and sutured over it that causes chronic muscle irritation and because of the fact that the closure is in tension.

Patients were regularly followed up to 1 year. Recurrence was observed only in patients with onlay mesh repair. 4 patients (10\%) patients out of 40 patients who underwent onlay mesh repair had a recurrence. Gleysteen found a recurrence rate to be $20 \%$ in onlay and $4 \%$ in pre-peritoneal mesh repairs. ${ }^{(15)}$ Retrospective study done by de Vries Reilingh et al. noticed a recurrence rate of $23 \%$ in 
cases that underwent onlay mesh repair, and no recurrence in patients with pre-peritoneal mesh repair. ${ }^{(16)}$

\section{Conclusion}

Time taken for surgery in onlay mesh repair is significantly less compared to pre-peritoneal mesh repair but complications of seroma formation, infection, chronic pain and higher recurrance rate associated with onlay mesh repair limits its use. Hence according to this study pre-peritoneal mesh repair is superior to onlay mesh repair.

\section{References}

1. Hershman M, Mann DV. In: Henry MM, Thompson JN, editors. Clinical Surgery. London: W.B. Saunders; 2001; 381:96.

2. Morgan EH, Anson BJ. Anatomy of region of inguinal hernia IV. The internal surface of the parietal layers. Q Bull Northwest Univ Med Sch 1942;16:20.

3. Bloom DA. Symposium: What is the best approach to the non-palpable testis? Contemp Urol 1992;4:39.

4. Bronsther B, Abrams MW, Elboim C. Inguinal hernias in children - a study of 1,000 cases and a review of the literature. $\mathbf{J}$ Am Med Womens Assoc 1972;27:522-5.

5. Rajput A, Gauderer MW, Hack M. Inguinal hernias in very low birth weight infants: Incidence and timing of repair. J Pediatr Surg 1992;27:1322-4.

6. Peevy KJ, Speed FA, Hoff CJ. Epidemiology of inguinal hernia in preterm neonates. Pediatrics 1986;77: 246-7.

7. Rowe MI, Clatworthy HW Jr. The other side of the pediatric inguinal hernia. Surg Clin North Am 1971;51:1371-6.

8. Scorer CG. The descent of the testis. Arch Dis Child 1964;39:605-9.

9. Cryptorchidism: An apparent substantial increase since 1960. John Radcliffe Hospital Cryptorchidism Study Group. Br Med J (Clin Res Ed) 1986;293:1401-4.
10. Fonkalsrud EW, Mengel W. The Undescended Testis. Chicago: Year Book Medical Publishers; 1981.

11. Greenall MJ, Evans M, Pollock AV. Midline or transverse laparotomy? A random controlled clinical trial. Part I: Influence on healing. $\mathrm{Br} \quad \mathrm{J}$ Surg 1980;67:188-90.

12. Bantu Rajsiddharth et al . Comparative Study of Onlay and Pre-Peritoneal Mesh Repair in the Management of Ventral Hernias. International Journal of Scientific Study 2015; 3:7

13. Carlson MA, Ludwig KA, Condon RE. Ventral hernia and other complications of 1,000 midline incisions. South Med J 1995;88:450-3.

14. Jack A. "Maingot's Abdominal operations", Edited by Zinner Michael J. and Schwartz Seymour I., Ellis Harold, 10th Edition, Appelton Century Crofts, 1997; 479-580.

15. Godara R, Garg P, Raj H, Singla SL. Comparative evaluation of "Sublay" versus "Onlay" meshplasty in ventral hernias. Indian $\mathbf{J}$ Gastroenterol 2006;25:222-3.

16. Gleysteen JJ. Mesh-reinforced ventral hernia repair: Preference for 2 techniques. Arch Surg 2009;144:740-5.

17. De Vries Reilingh TS, van Geldere D, Langenhorst B, de Jong D, van der Wilt GJ, van Goor $\mathrm{H}$, et al. Repair of large midline incisional hernias with polypropylene mesh: Comparison of three operative techniques. Hernia 2004;8:56-9. 